\title{
Retrograde transcatheter closure of ventricular septal defect with Amplatzer Duct Occluder II
}

\author{
Brina Suligoj ${ }^{1}$, Natasa Cernic ${ }^{2}$, Metka Zorc ${ }^{1}$, Marko Noc ${ }^{3}$, Saibal Kar ${ }^{4}$ \\ ${ }^{1} \mathrm{MC}$ Medicor, Izola, Slovenia \\ ${ }^{2}$ Department of Internal Medicine, General Hospital Izola, Izola, Slovenia \\ ${ }^{3}$ Center for Intensive Internal Medicine, University Medical Center, Ljubljana, Slovenia \\ ${ }^{4}$ Cardiovascular Intervention Center, Cedars-Sinai Heart Institute, Los Angeles, USA
}

Adv Interv Cardiol 2016; 12, 2 (44): 177-178

DOI: 10.5114 /aic.2016.59371

One of the most feared complications of transcatheter closure of a perimembranous ventricular septal defect (VSD) by the Amplatzer membranous occluder is atrioventricular (AV) block, occurring in $3 \%$ to $20 \%$ of cases [1, 2]. Atrioventricular block may occur immediately due to squeezing effects of disks or late due to device-induced inflammation and fibrous tissue formation [3].

We herein describe a 14-year-old girl in whom an alternative method with the softer Amplatzer Duct Occluder, which may overcome the above limitations, was used. The indication for VSD closure was based on left ventricular volume overload documented by transthoracic echocardiography (TTE) and the fact that she wanted to continue with professional sport activity.

The procedure was performed under general anesthesia with fluoroscopic and transesophageal echocardiography (TEE) guidance. Ventricular septal defect was confirmed by left ventriculography (Figure $1 \mathrm{~A}$ ) and TEE assessing the interventricular septum in multiple planes. The largest VSD diameter was $5 \mathrm{~mm}$, and the distance from the upper VSD margin to the aortic valve was $13 \mathrm{~mm}$ (Figure $1 \mathrm{~B}$ ). Since the VSD diameter was $<6.5 \mathrm{~mm}$ and the distance between the upper margin and aortic valve was > $3 \mathrm{~mm}$, closure with Amplatzer Duct Occluder II (ADO II, St. Jude Medical, St. Paul, Minnesota, USA) was selected $[4,5]$. A 6 Fr JR 4 guiding catheter (Launcher, Medtronic Inc, Minneapolis) was advanced from the right femoral artery to the left side of the VSD, which was crossed by angled Terumo wire (Terumo Corporation, Tokyo, Japan). The guiding catheter was slowly advanced across the VSD to the right ventricle and loaded with the ADO II $6 / 6 \mathrm{~mm}$ attached to a $5 \mathrm{Fr}$ TorqVue LP
(St. Jude Medical, St. Paul, Minnesota, USA). The right retention disk was deployed and the assembly withdrawn so that the disk was aligned with the septum. The waist and left retention disk were then sequentially deployed. Once a stable position and no interference with aortic and tricuspid valves were confirmed with TEE, the delivery system was detached and removed together with the guiding catheter. Left ventriculography showed minimal intra-device residual shunting (Figure $1 \mathrm{C}$ ). Transthoracic echocardiography revealed both retention disks to be flat and in an appropriate position without interference with the aortic valve (Figure $1 \mathrm{D}$ ). The fluoroscopy time was $5.26 \mathrm{~min}$. The postprocedural course was uneventful. After 49 days, TTE revealed good device position without residual shunt. Left ventricular end diastolic diameter decreased from 48 to $44 \mathrm{~mm}$, left ventricular volume index from 65 to $51 \mathrm{ml} / \mathrm{m}^{2}$ and left atrial surface area from 20 to $14 \mathrm{~cm}^{2}$ compared to measurements before closure. After $>2$ years, the patient continues to be in good condition without AV conduction block.

In conclusion, we believe that retrograde closure of the membranous VSD with the ADO II should be considered if the diameter of the VSD, its morphology and the distance from the aortic valve documented by TEE are within the recommended range [4]. The procedure is substantially less invasive and faster than standard closure with the membranous Amplatz VSD occluder, without the need for an AV loop.

\section{Conflict of interest}

The authors declare no conflict of interest.

\section{Corresponding author:}

Marko Noc, Center for Intensive Internal Medicine, University Medical Center Ljubljana, 7 Zaloska St, 1000 Ljubljana, Slovenia, phone: +38 615222296, e-mail: marko.noc@mf.uni-lj.si

Received: 16.10 .2015 , accepted: 12.11 .2015$. 

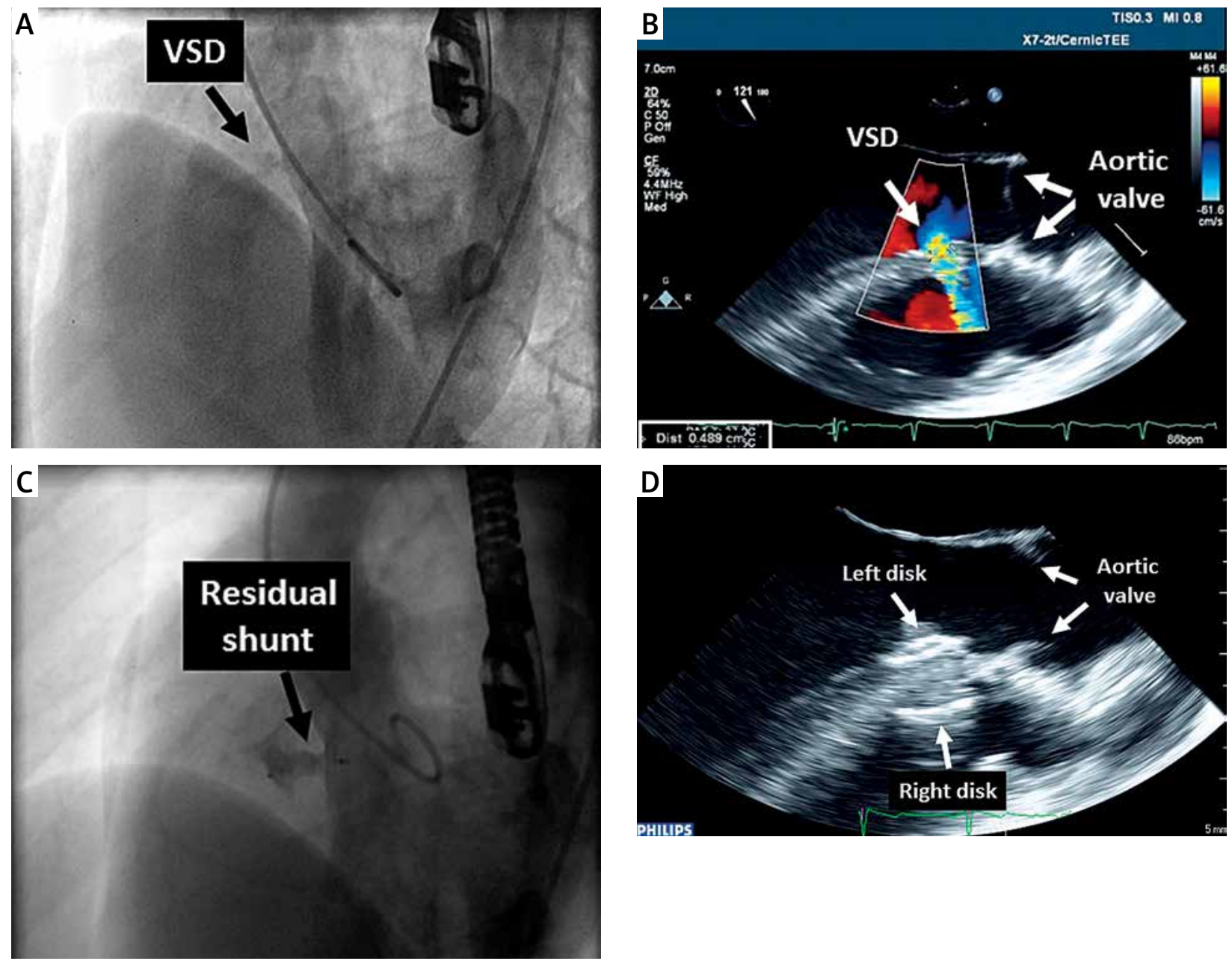

Figure 1. Preprocedural left ventriculography (left anterior oblique view) showing perimembranous VSD with left-to-right shunting $(\mathbf{A})$ and TEE $\left(121^{\circ}\right)$ with color flow across the VSD with maximal diameter of $5 \mathrm{~mm}$ and $13 \mathrm{~mm}$ distance to aortic valve (B). Postprocedural left ventriculography showing small residual shunt through central part of ADO II (C) and TEE showing both retention disks to be flat and well aligned to the septum without interference with the aortic valve (D)

\section{References}

1. Carminati M, Butera G, Chessa M, et al.; for Investigators of the European VSD Registry. Transcatheter closure of congenital ventricular septal defects: results of the European Registry. Eur Heart J 2007; 28: 2361-8.

2. Predescu D, Chaturvedi RR, Friedberg MK, et al. Complete heart block associated with device closure of perimembranous ventricular septal defects. J Thorac Cardiovasc Surg 2008; 336: 1223-8.

3. Ghaderian $M$, Merajile $M$, Mortezaeian $H$, et al. Efficacy and safety of using Amplatzer ductal occluder for transcatheter closure of perimembranous ventricular septal defects in pediatrics. Iran J Pediatr 2015; 25: e386.

4. Koneti NR, Sreeram N, Penumatsa RR, et al. Transcatheter retrograde closure of perimembranous ventricular septal defects in children with the Amplatzer Duct Occluder II device. J Am Coll Cardiol 2012; 60: 2421-2.
5. Wierzyk A, Szkutnik M, Fiszer R, et al. Transcatheter closure of ventricular septal defects with nitinol wire occluders of type patent ductus arteriosus. Postep Kardiol Inter 2014; 10: 21-5. 